Literatura y Lingüística $\mathrm{N}^{\circ} 24$

ISSN 0716-5811 / pp. 161-182

\title{
Análisis descriptivo de Textos Escolares de Lenguaje y Comunicación*
}

\author{
Felipe Pereira Henríquez** \\ Guillermo González Hernández***
}

\section{Resumen}

Este artículo presenta desde una perspectiva multimodal la fundamentación teórica y la aplicación de un Modelo de Análisis Descriptivo de Textos Escolares (MADETEC). El objetivo principal de este modelo es describir en los textos escolares las relaciones entre el lenguaje verbal escrito y el lenguaje icónico que se presentan en este tipo de materiales didácticos. En lo referente a la fundamentación teórica, MADETEC se constituye a partir de cinco componentes: estructural; identificatorio; genérico; icónico y diseño. Cada uno de estos se focaliza en distintos aspectos del texto escolar, permitiendo describir desde la identificación de las secciones de este macro género discursivo hasta las relaciones entre las imágenes y los textos escritos. La aplicación de este se realiza en un corpus de 2 textos escolares de $5^{\circ}$ y $6^{\circ}$ básico del sector de Lenguaje y Comunicación.

Palabras clave: texto escolar, funciones y tipos de imágenes, multimodalidad

\section{Descriptive analysis of language and communication textbooks}

\begin{abstract}
From a multimodal perspective, this article presents the theoretical principles and the application of a Descriptive Analysis Model for Textbooks (DAMT). The main objective of this model is to describe the relation between verbal and iconic language in textbooks. Regarding theoretical principles, DAMT is built upon five components: structural, identificatory, generic, iconic, and design. Each one of them is focused on different aspects of the textbook, allowing the description from the identification of the sections of this macro-genre to the relation between images and written texts. The process is carried out in two textbooks belonging to $5^{\circ}$ and $6^{\circ}$ grade of primary school in the area of Lenguaje y Comunicación.
\end{abstract}

Key words: textbook, functions and kind of images, multimodality

Recibido: 05-03-2011 Aceptado: 15-04-2011

El presente trabajo se enmarca en la investigación de Post Doctorado n 3090061, financiada por Fondecyt-Conicyt, durante los años 2009-2010.

* Doctor en Lingüística PUCV. Profesor Escuela de Pedagogía Pontificia Universidad Católica de Valparaíso: felipe.pereira@ucv.cl; fepelipe@gmail.com

*** Licenciado en Lengua y Literatura Hispánica. gmo.gonzalez.h@gmail.com

161 
Análisis descriptivo de Textos Escolares de Lenguaje y Comunicación / Felipe Pereira

Henríquez y Guillermo González

\section{Introducción}

En la actualidad, los textos del ámbito educativo y de otros contextos no utilizan el lenguaje verbal escrito como el único modo de representación y transmisión de significados. La frecuente utilización de textos, tanto digitales como impresos, que incluyen imágenes ha crecido en cantidad y en complejidad. En este marco, los libros de texto o textos escolares -conceptualizados como géneros discursivos producidos para ser utilizados en contextos específicos de enseñanza-aprendizaje- son uno de los géneros que más imágenes presenta en su diagramación (Colas Bravo, 1989; Kress, 2003).

Una breve revisión de la literatura especializada en esta área y desde el contexto Inglés, permite constatar variadas experiencias en las que se señala cómo se aprende a partir del modo escrito y de las imágenes (Eubanks, 1999; Jewitt, 2003; Jewitt \& Kress, 2003; Kress 2003, 2004, 2005; Kress y van Leeuwen, 1996, 2001; Maverns, 2003). Estudios producidos en lengua española también dan cuenta de la utilización de imágenes en los textos, poniendo un especial énfasis en los textos escolares. Trabajos como los de Alzate (2000); Colas Bravo (1989); Otero y Greca (2004); Perales y Romero (2005); Prendes (1996; 2001); Prendes y Solano (2001); Pro (2003); Scolari y March (2004); Vilches (1995), han abordado el vínculo texto/imagen asumiendo que las ilustraciones, fotografías y gráficos tienen un valor significativo en la configuración de estos materiales didácticos.

Como se desprende de los párrafos anteriores, pese a que existen variadas investigaciones en esta línea, hay pocas herramientas que permiten describir los textos escolares desde una perspectiva multimodal. En este sentido, se puede mencionar que se han realizado estudios que analizan las imágenes de los textos escolares independiente del lenguaje verbal escrito, pero no la interacción conjunta de ambos modos de representación.

En este artículo se aborda esta problemática a partir de un objetivo general: Presentar y aplicar un Modelo Multimodal de Análisis Descriptivo de Textos Escolares (MADETEC) que permita analizar los textos de estudio y otros materiales multimodales que se utilizan tanto en contextos educativos como en otros. 
Literatura y Lingüística ${ }^{\circ}{ }^{\circ 24}$

\section{Marco de referencia}

\section{El texto escolar}

El texto escolar, libro de texto (Colas Bravo, 1989; Otero \& Greca, 2004) o manual escolar (Prendes, 1996; 2001), es uno de los recursos didácticos básicos y prioritarios de mayor tradición en las aulas. Ni la inclusión de nuevas tecnologías ni las críticas que lo consideran un elemento deformante, impositivo y moralizante han logrado quebrantar esta posición (Colas Bravo, 1989). En esta misma línea, Prendes (2001) señala que este es un producto editorial bimedia, elaborado particularmente para la enseñanza en las escuelas, es decir, para su utilización específica como auxiliares de la enseñanza y promotores del aprendizaje. Esta misma autora, reseñando un trabajo de 1981 de Richadau, señala que "un manual escolar es un material impreso, estructurado, destinado a utilizarse en un determinado proceso de aprendizaje y formación" (Prendes, 2001: 2)

En esta misma perspectiva, Eyzaguirre y Fontaine (1997) plantean que:

Los textos escolares dan una forma concreta al currículum y permiten que el profesor pueda planificar sus clases. Son una herramienta sumamente eficaz para actualizar y perfeccionar la información del profesorado. A la vez permiten a los alumnos estudiar independientemente si es necesario y paliar las deficiencias educacionales de su familia y escuela (Eyzaguirre y Fontaine, 1997: 369).

En otro estudio Fontaine y Eyzaguirre (1997:357) señalan que "el texto de estudio es una obra diseñada para usarla en clases y provee una introducción sistemática a una disciplina o asignatura".

Continuando con esta idea, el Ministerio de Educación de Chile (Mineduc) en su Política de Textos escolares 2008 plantea que:

El Texto Escolar cumple una función central en la tarea educativa de los docentes, tanto en el aula como en otros espacios de aprendizaje (como la biblioteca o el hogar). Para los estudiantes juega fundamentalmente un rol articulador en el proceso de aprendizaje. Los docentes, en tanto, lo utilizan junto a la guía didáctica para planificar, preparar y desarrollar sus clases. Además, en sectores de mayor vulnerabilidad socioeconómica y cultural, el texto representa un instrumento de equidad y enriquecimiento cultural para las familias (Mineduc, 2008: 3). 
Análisis descriptivo de Textos Escolares de Lenguaje y Comunicación / Felipe Pereira

Henríquez y Guillermo González

Como una forma de ampliar las perspectivas presentadas hasta ahora, se señala la posición de Colas Bravo (1989), quien señala que el texto escolar es un producto de gran interés científico y social que ha sido estudiado y analizado desde diferentes perspectivas teóricas y prácticas. En este sentido, la misma autora, refiriéndose a un trabajo de Carroll producido en 1974, señala que el libro de texto tiene cuatro características esenciales: i) es un material asequible, ii) eficaz, iii) que permite un nivel de abstracción que difícilmente se alcanza con otros medios, y iv) que aporta experiencias mediatas, vicariales y abstractas esenciales en el aprendizaje.

Desde una visión diferente a las ya señaladas, focalizada en la transmisión de la hegemonía, Ajagan (2007) señala que:

Los textos escolares no son productos culturales independientes de los procesos hegemónicos, sino que contribuyen a reproducir la cultura dominante, pero también pueden convertirse en escenario de conflictos en la constante producción/reproducción de conocimientos e ideologías (Ajagan, 2007: 326).

\section{Marco teórico del Modelo Multimodal de Análisis Descriptivo de Textos Escolares (MADETEC)}

\subsection{Descripción}

MADETEC es un instrumento de análisis multimodal de los textos escolares diseñado en función de los textos de Lenguaje y Comunicación del segundo ciclo básico. El objetivo principal de este modelo es describir el texto escolar en cuanto a los géneros discursivos que lo componen, las imágenes presentes en este, el diseño del mismo y las relaciones subyacentes entre las ilustraciones y el texto verbal. Esto, en función del nivel cognitivo de los estudiantes. El foco de esta herramienta es el análisis descriptivo, sin embargo, se reconoce una potencialidad evaluativa de este tipo de materiales didácticos. En términos metodológicos, MADETEC permite realizar una descripción cuantitativa de la cantidad de imágenes y las funciones predominantes de estas, así como también de los géneros discursivos que componen los textos de estudio.

Los aspectos que este modelo no considera son: i) el currículum oculto, es decir, las visiones ideológicas y hegemónicas que subyacen tanto a los géneros discursivos escritos como a las imágenes; ii) la cobertura de los OF y CMO del currículum nacional, y iii) este modelo no contempla 
el análisis de la calidad de las actividades, de la metodología propuesta, de la coherencia con la guía didáctica del profesor ni la calidad de los instrumentos de evaluación. La omisión intencionada de estos se debe a que este modelo fue elaborado para describir y caracterizar los textos escolares.

\subsection{Estructura de MADETEC}

En la Figura 1, se presenta la estructura del MADETEC y cada uno de los componentes. Estos se describen en los apartados siguientes.

Figura 1: Estructuración del MADETEC.

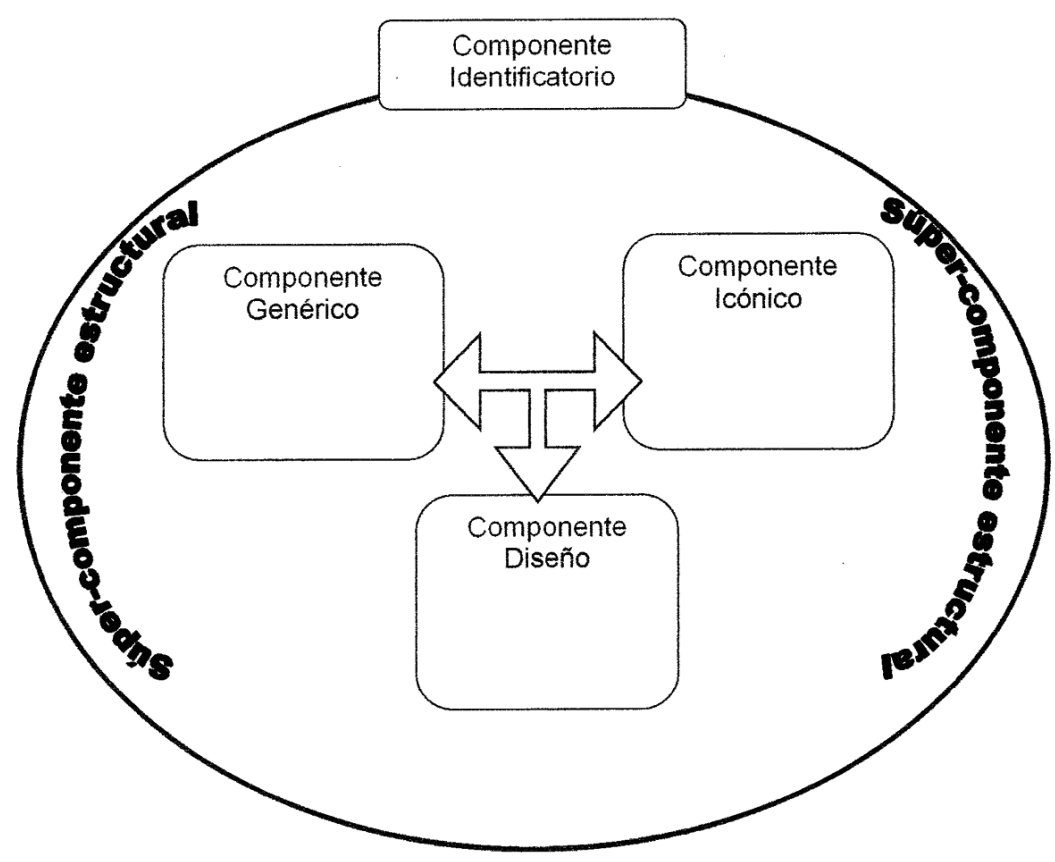

\subsubsection{Súper Componente estructural}

El súper componente estructural permite dar cuenta de la macro y la micro estructura del libro de texto. Ambos términos, en esta sección del modelo se conceptualizan desde la perspectiva metalexicográfica de Haensch (1982; 1997), quien plantea que la macroestructura es la organización general, mientras que la microestructura es la organización en el nivel interno del texto.

MADETEC asume que la Macroestructura es la organización general del texto escolar, conformada por la portada, el índice, la estructura del 
Análisis descriptivo de Textos Escolares de Lenguaje y Comunicación / Felipe Pereira

Henríquez y Guillermo González

texto, el cuerpo (unidades) y la sección de anexos. La Microestructura o cuerpo se define como el conjunto de unidades separadas en secciones que a su vez se componen por actividades, recursos, evaluaciones y contenidos conceptuales. De acuerdo a la definición del Componente Textos Escolares de la Unidad de Gestión y Currículo del Mineduc, las actividades son las diferentes instancias en las que el estudiante interactúa con los Objetivos Fundamentales y los Contenidos Mínimos Obligatorios del nivel y subsector correspondiente según el Currículum Nacional. En el texto escolar, suelen estar presentadas en segunda persona dando instrucciones específicas a los alumnos y acciones concretas a realizar con el fin de desarrollar habilidades. En el ámbito de Lenguaje, por ejemplo, las diferentes actividades propuestas cubren las tres áreas de desarrollo (Comprensión, Producción y Comunicación Oral), permitiendo a los estudiantes la apropiación del Currículum y la cobertura de los aprendizajes esperados.

\subsubsection{Componente identificatorio}

El componente identificatorio corresponde a los datos de identificación del texto de estudio, estos son: el nivel de enseñanza al que se adscribe, el subsector de aprendizaje, la editorial que lo produce, el año de edición y los autores. Este componente permite contextualizar el texto escolar dentro de un área específica del conocimiento, en un espacio de tiempo y un nivel de aprendizaje determinado.

\subsubsection{Componente genérico}

El género es un concepto sujeto a controversia, difícil de delimitar y que tiene una historia que se puede remontar a las ideas aristotelianas relacionadas con la retórica clásica. Desde variadas perspectivas, la literatura especializada ha entendido este término como un sinónimo de "tipo" o "clase" textual debido a que en las situaciones de comunicación orales o escritas, se presentan ciertas tendencias regulares en los comportamientos discursivos de las personas.

De acuerdo con Ciapuscio (1994) y Calsamiglia y Tusón (1999), el género es definido como un hecho sociocultural y discursivo cuyo "uso se ha extendido para clasificar gran parte de los productos culturales en los que el uso de la palabra es un elemento fundamental" (Calsamiglia \& Tusón, 1999: 252).

Desde la perspectiva de Bajtin (1979) el género está condicionado por cuatro factores: el tema, la estructura interna, el registro y la estabilidad

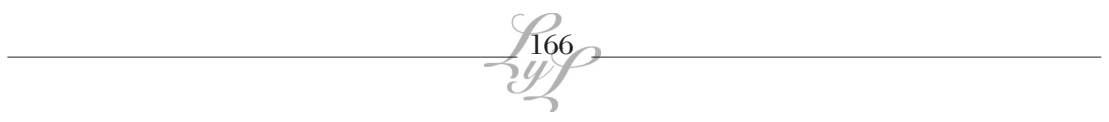


relativa de todos estos. De esta manera, este investigador distingue entre los géneros primarios o simples (la conversación en sus diferentes formas) y los secundarios, producto de la elaboración intelectual (literarios, periodísticos y científicos).

Parodi (2008) plantea que "el género constituye una constelación de potencialidades de convenciones discursivas, sustentada por los conocimientos previos de los hablantes-escritores y oyentes-lectores (almacenados en la memoria de cada sujeto), a partir de constricciones y parámetros contextuales, sociales y cognitivos" (Parodi, 2008: 26). La postura de este autor recoge los principios de Hymes (1972), quien señala que los usuarios de los textos poseen una competencia construccional y otra discursiva que les permite, por una parte, saber cómo construir los textos de acuerdo a las situaciones de comunicación $y$, por otra, qué géneros son más apropiados para ciertas situaciones de comunicación.

Como se desprende de los párrafos anteriores, ante el concepto de género no existe consenso desde las diferentes perspectivas que lo definen. En otros términos, este concepto es problemático, difuso y difícil de determinar. Pese a esto, diferentes autores han planteado que existen rasgos constitutivos que definen Género, tales como: el modo de organización discursiva; el macro propósito comunicativo y el Tema. (Calsamiglia \& Tusón, 1999; Bajtin, 1979; Parodi, Venegas, Ibáñez \& Gutiérrez, 2008).

\subsubsection{Componente icónico}

La imagen es la representación de un objeto del mundo real mediante diferentes técnicas (dibujo, fotografía y/o pintura), dicha representación puede ser mediante imágenes estáticas (fijas) o dinámicas (con movimiento). Desde otra perspectiva, Kress (2003; 2004; 2005) y Colle (1993) plantean que la imagen no solo representa la realidad sino que es otro modo de representación con características similares al lenguaje verbal en sus modalidades escrito $u$ oral.

Desde una perspectiva didáctica, Perales y Romero (2005) señalan que las imágenes son elementos constituyentes del aprendizaje y funcionan como transmisoras de conocimiento que no solo representan la realidad sino que conceptos más abstractos.

Por último, se presenta la postura de Pereira (2007), quien señala lo siguiente: 
Análisis descriptivo de Textos Escolares de Lenguaje y Comunicación / Felipe Pereira

Henríquez y Guillermo González

... la lectura de la imagen puede considerase como una forma de alfabetización debido a que los lectores deben ser capaces de desarrollar competencias para identificar los elementos constitutivos de estas y sus posibilidades de combinación. También, deben ser capaces de comprender su proceso de funcionamiento, para leerlas desde una perspectiva crítica. En otros términos, el lector de la imagen deber ser capaz de reconocer que toda ilustración tiene una intención que puede estar determinada por el contexto en el que se presente. (Pereira, 2007: 97-98)

\subsubsection{Componente diseño}

Este componente es el que está más relacionado con el análisis multimodal propiamente tal, debido a que en este se analizan las relaciones entre más de un modo de representación. La literatura especializada lo ha denominado como Diagramación (Colas Bravo, 1989; Alzate, 2000). Según estos autores, la diagramación o los elementos paratextuales se relaciona con los títulos, los subtítulos, la paginación, las notas, las referencias, los espacios en blanco, las imágenes y las notas al pie de página. Este componente no es tratado en este artículo por razones de espacio, razón por la cual no se profundizará en el mismo.

\section{Operacionalización de los diferentes componentes teóricos}

En esta sección se operacionaliza la definición de textos escolares, así como la descripción teórica de los distintos componentes de MADETEC.

Considerando todas las perspectivas planteadas anteriormente, en este artículo se asume que el texto escolar es un macro-género discursivo multimodal utilizado en contextos educativos formales tales como las escuelas y los liceos. Esta herramienta, que se compone por imágenes y lenguaje verbal y que puede presentarse en el medio impreso o digital, tiene como propósito principal ser un instrumento de planificación para docentes y de transporte del Currículum Nacional para los estudiantes, de acuerdo a la disciplina (subsector) y nivel correspondiente.

En términos estructurales este macro-género, inserto en el ámbito del discurso pedagógico, está compuesto por una macro y una microestructura. La primera, se refiere a la organización más general en la que se consideran la portada, el índice, la estructura del texto, el cuerpo (unidades) y la sección de anexos. En términos microestructurales, el texto escolar está constituido por unidades que a su vez contienen

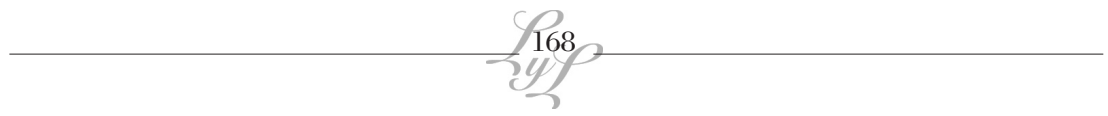


actividades, recursos, evaluaciones y contenidos conceptuales. En el plano de los recursos, el libro de texto contiene diversos géneros más específicos que se materializan en actividades que los estudiantes deben desarrollar para adquirir los objetivos fundamentales y los contenidos mínimos obligatorios propuestos en el currículum nacional. Es de suma relevancia mencionar que la aplicación de MADETEC se realiza sobre la microestructura del texto (unidades) y no en los otros constituyentes.

Los diferentes géneros discursivos (Asociados al Componente Genérico) que MADETEC permite analizar según su modo de organización, son: el género narrativo, el descriptivo, el argumentativo, el expositivo y las actividades. Respecto de los cuatro primeros no se discutirá ni se dará mayores antecedentes en este escrito, puesto que están ampliamente discutidos en la literatura especializada. El quinto, en cambio, es un género sobre el que no hay tantos antecedentes teóricos, pero que resulta trascendental al momento de analizar textos escolares de cualquier subsector. Las actividades, de acuerdo con la perspectiva del autor, son las instancias en las que los estudiantes interactúan con el texto escolar no solo como lectores que construyen significados de los textos, sino que desde una perspectiva didáctica. En otras palabras, las actividades son indicaciones directas, en primera o segunda persona, que tienen por objetivo final adquirir contenidos conceptuales y la aplicación de los OF y CMO del subsector correspondiente.

El Componente Icónico de este modelo considera los tipos y las funciones de las imágenes. Para los fines de este artículo y con la finalidad de analizar textos escolares, específicamente, se ha configurado una taxonomía de imágenes que aborda tanto el tipo como la función que estas cumplen en relación con el modo escrito.

La clasificación según el tipo considera: Las fotografías, las ilustraciones, las capturas de pantalla, las caricaturas, los gráficos; los esquemas y los mapas. A continuación se explica brevemente en qué cosiste cada una de estas.

Fotografías: son las imágenes que más guardan un paralelismo con aquello que representan, fundamentalmente porque si bien pueden presentar un componente artístico, se destinan a ofrecer una representación lo más directa posible de personajes célebres, montajes experimentales u objetos del mundo real (Otero \& Greca, 2004).

- Ilustraciones: También representan un nivel de similitud con el o los objetos que representan, sin embargo, se diferencian de las fotografías por el trazo manual de líneas y formas (Otero \& Greca, 2004). 
Análisis descriptivo de Textos Escolares de Lenguaje y Comunicación / Felipe Pereira

Henríquez y Guillermo González

- Capturas de pantalla: Esta categoría presenta similitudes tanto con las fotografías como con las ilustraciones. Sin embargo, no pertenecen a una ni a otra. Las características principales de este tipo es que son imágenes tomadas del medio digital (especialmente el computador). Algunos de las capturas más recurrentes son las presentaciones de Power Point, capturas de conversaciones por Chat o vistas del escritorio o de algún conjunto de herramientas computacionales.

- Caricaturas: Son dibujos que integran viñetas con diálogo o que conforman pequeñas historias. Son similares a lo que comúnmente se conoce como Cómic, aunque en esta definición específica, también permiten fotografías.

- Gráficos: Son representaciones de elementos con un nivel icónico mucho menor en comparación con fotografías e ilustraciones. Representan principalmente datos numéricos, por ende se trata de una representación más abstracta del objeto.

- Esquemas: Son representaciones visuales que integran información icónica como verbal. En esta categoría se encuentran los mapas conceptuales, los esquemas propiamente tales, los diagramas, entre otros.

- Mapas: Los mapas son un tipo de imágenes cuya funcionalidad se basa en la exactitud de sus datos en relación al territorio representado.

La taxonomía de acuerdo a las principales funciones que cumplen las imágenes en los textos escolares es la siguiente:

- Función de atención y motivación: en este caso la imagen que acompaña al texto busca atraer la atención del lector, motivándolo a realizar y continuar la lectura.

- Función estética: la imagen sólo se presenta para adornar la página marco por lo tanto no existe una relación directa entre este modo de representación con el texto verbal escrito.

- Función de complementación: la imagen ayuda a entregar información referente al texto verbal escrito y, por ende, permite una mejor comprensión de este, sin embargo, no es esencial que se presente junto con este. En otras palabras tanto la imagen como el texto verbal escrito contienen la misma información.

Función informativa: la imagen aporta información al texto verbal escrito dado que posee elementos que entregan una información anexa. Su integración dentro del texto es importante, ya que muchas veces la información que presenta pone al texto en un lugar secundario.

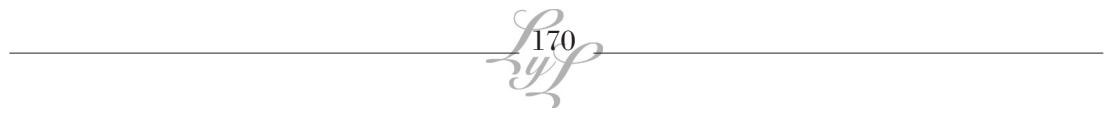




\section{Metodología, procedimiento de aplicación y resultados}

\section{Metodología}

La metodología empleada es de tipo cuantitativo, con un alcance descriptivo. El corpus de textos analizados son los textos escolares de $5^{\circ}$ y $6^{\circ}$ básico de Lenguaje y Comunicación de la editorial Cal y Canto, utilizados durante el año 2009 en los establecimientos municipalizados chilenos.

\section{Procedimiento de aplicación}

La aplicación de MADETEC se realiza en distintos pasos.

- En primer lugar, se identificaron las distintas unidades del texto escolar, dado que MADETEC trabaja sobre la microestructura de estos materiales didácticos.

- Luego se identificaron todas las imágenes de acuerdo con su tipo.

- Un tercer paso, fue relacionar las imágenes con los textos escritos a partir del tópico (tema) que estas presentaban. Esto implicó determinar los elementos icónicos más relevantes de las imágenes mediante un análisis denotativo centrado en las formas, las figuras y los colores.

- Una vez establecida la relación entre el material lingüístico y el visual se determinó el género de los textos escritos.

- Posteriormente, en base al contenido de la imagen, se determinó la función de esta en relación con el texto que acompañaba.

\section{Resultados y discusión}

A continuación se describen los principales resultados obtenidos mediante la aplicación de MADETEC. Cabe mencionar que estos resultados son descriptivos y dan cuenta, por una parte, de los tipos de imágenes detectados al interior de los textos escolares, mientras que por otra de las funciones que estas cumplen.

\subsection{Tipos de imágenes}

En las Tablas 1 y 2 se muestra la distribución de las imágenes que presentan los textos de estudio en $5^{\circ}$ y $6^{\circ}$ básico, en cada una de sus unidades. 
Análisis descriptivo de Textos Escolares de Lenguaje y Comunicación / Felipe Pereira Henríquez y Guillermo González

Tablas 1 y 2: Distribución de las imágenes en relación con las unidades de aprendizaje

\begin{tabular}{|l|c|c|c|c|c|c|c|}
\hline $5^{\circ}$ Básico & Unidad 1 & Unidad 2 & Unidad 3 & Unidad 4 & Unidad 5 & Unidad 6 & Total \\
\hline Fotografías & 4 & 3 & 13 & 10 & 17 & 4 & 51 \\
\hline Ilustraciones & 27 & 22 & 21 & 30 & 15 & 28 & 143 \\
\hline Caricaturas & 6 & 5 & 6 & 4 & 5 & 6 & 32 \\
\hline Capturas & 0 & 4 & 0 & 0 & 1 & 0 & 5 \\
\hline Mapas & 0 & 0 & 0 & 0 & 0 & 0 & 0 \\
\hline Esquemas & 3 & 4 & 0 & 2 & 0 & 1 & 10 \\
\hline Total & 40 & 38 & 40 & 46 & 38 & 39 & 241 \\
\hline
\end{tabular}

\begin{tabular}{|l|c|c|c|c|c|c|c|}
\hline $6^{\circ}$ Básico & Unidad 1 & Unidad 2 & Unidad 3 & Unidad 4 & Unidad 5 & Unidad 6 & total \\
\hline Fotografías & 3 & 12 & 4 & 16 & 21 & 5 & 61 \\
\hline Ilustraciones & 22 & 34 & 23 & 20 & 16 & 15 & 130 \\
\hline Caricaturas & 10 & 7 & 8 & 9 & 4 & 8 & 46 \\
\hline Capturas & 0 & 0 & 0 & 1 & 0 & 0 & 1 \\
\hline Mapas & 0 & 0 & 0 & 0 & 0 & 0 & 0 \\
\hline Esquemas & 2 & 3 & 1 & 2 & 0 & 1 & 9 \\
\hline Total & 37 & 56 & 36 & 48 & 41 & 29 & 247 \\
\hline
\end{tabular}

Como puede apreciarse, la cantidad de imágenes en $5^{\circ}$ básico es de 241 y en $6^{\circ}$ básico de 247 . La distribución más específica de estas para $5^{\circ}$ básico es la siguiente: 51 fotografías que equivalen al 21\% del total; 32 caricaturas (13\%); 5 capturas de pantalla, lo que representa solo el $2 \%$ de la muestra; 143 ilustraciones (60\%); 10 esquemas (4\%) y ningún mapa. En $6^{\circ}$ Básico la distribución es la siguiente: 61 fotografías (26\% del total); 46 caricaturas (19\%); 1 captura de pantalla, es decir menos del 1\%; 130 ilustraciones, que equivalen al 55\% de la muestra de este curso; 9 esquemas, correspondientes al 3,6\%, y ningún mapa.

A partir de estos datos se plantea que en los textos escolares de ambos cursos la presentación de ilustraciones es superior al 50\% del total de imágenes. De acuerdo con la definición conceptual estas captan la realidad, pero con un trazo manual, es decir, son dibujos realizados "a mano alzada" o por medios computacionales. Una primera hipótesis al respecto, es que la utilización de las ilustraciones se debe a que los fenómenos que ocurren en la vida cotidiana son más sencillos de captar por este tipo de imágenes, dado que dan la posibilidad de dibujar y por lo tanto recrear las situaciones comunicativas u otras.

Respecto de la fotografías, se puede mencionar que estas se utilizan recurrentemente en las distintas unidades, pero su utilización no supera el $30 \%$ en ambos textos. De todas formas, se presenta una variación entre $5^{\circ}$ y $6^{\circ}$ básico lo que permite sugerir que los autores de los textos de 
estudio, en la medida que se avanza en los niveles, incluyen imágenes más complejas y más concretas en relación con la realidad.

Las Caricaturas, por su parte, se utilizan en todas las unidades analizadas y en un porcentaje cercano al 20\%. Según la definición conceptual, estas pueden ser fotografías o dibujos acompañados de viñetas de texto verbal (nubes de texto como se han denominado al referirse al cómic). Estos recursos son recurrentes en los textos de estudio analizados puesto que se emplean para explicar algunos de los contenidos conceptuales de manera más sencilla, o incluso para reafirmar algunas aseveraciones dadas en los textos de estudio.

Continuando con esta descripción, tanto los esquemas como las capturas de pantalla se presentan en baja proporción. Respecto de los primeros se puede mencionar que aunque el número de esquemas es relativamente bajo en proporción con los otros tipos de imágenes, estos aparecen en casi todas las unidades de ambos textos de estudio. Una explicación a esta situación se debe a que en casi todas las unidades observadas se entregan esquemas o mapas conceptuales (que también están en esta categoría) a modo de resumen o síntesis de los contenidos que se han trabajado, lo que en cierta forma es una manera de apoyar a los estudiantes en sus métodos de estudio. Las capturas, por su parte, solo se presentan en las unidades 2 y 5 para $5^{\circ}$ básico y en la unidad 4 para $6^{\circ}$. En los casos comentados, este tipo de imágenes representan capturas de Power Point, de un Blog y de una Página Web, respectivamente. Su mínima presentación en los textos de estudio analizados se debe a que estas solo se utilizan como ejemplos de esos géneros digitales, sin embargo no tiene una mayor incidencia ni tampoco se trabaja en profundidad con las mismas.

Por último, los mapas no presentan ninguna ocurrencia en los textos analizados. Se asume que dada la naturaleza de la disciplina este tipo de imágenes no es relevante para transmitir los contenidos ni tampoco para potenciar las habilidades de los niveles estudiados, las que se asocian a los diferentes Objetivos Fundamentales y a los Contenidos Mínimos Obligatorios. Se hipotetiza que esta situación debiese cambiar drásticamente al analizar textos de otras disciplinas tales como Inglés o comprensión del Medio Social.

Complementando estos resultados, se agrega la relación entre los distintos tipos de imágenes con los géneros discursivos a los que acompañan al interior de los textos escolares. Los gráficos 1 y 2 muestran esta dispersión. 
Análisis descriptivo de Textos Escolares de Lenguaje y Comunicación / Felipe Pereira

Henríquez y Guillermo González

Gráficos 1: Tipos de imágenes y Géneros en $5^{\circ}$ básico

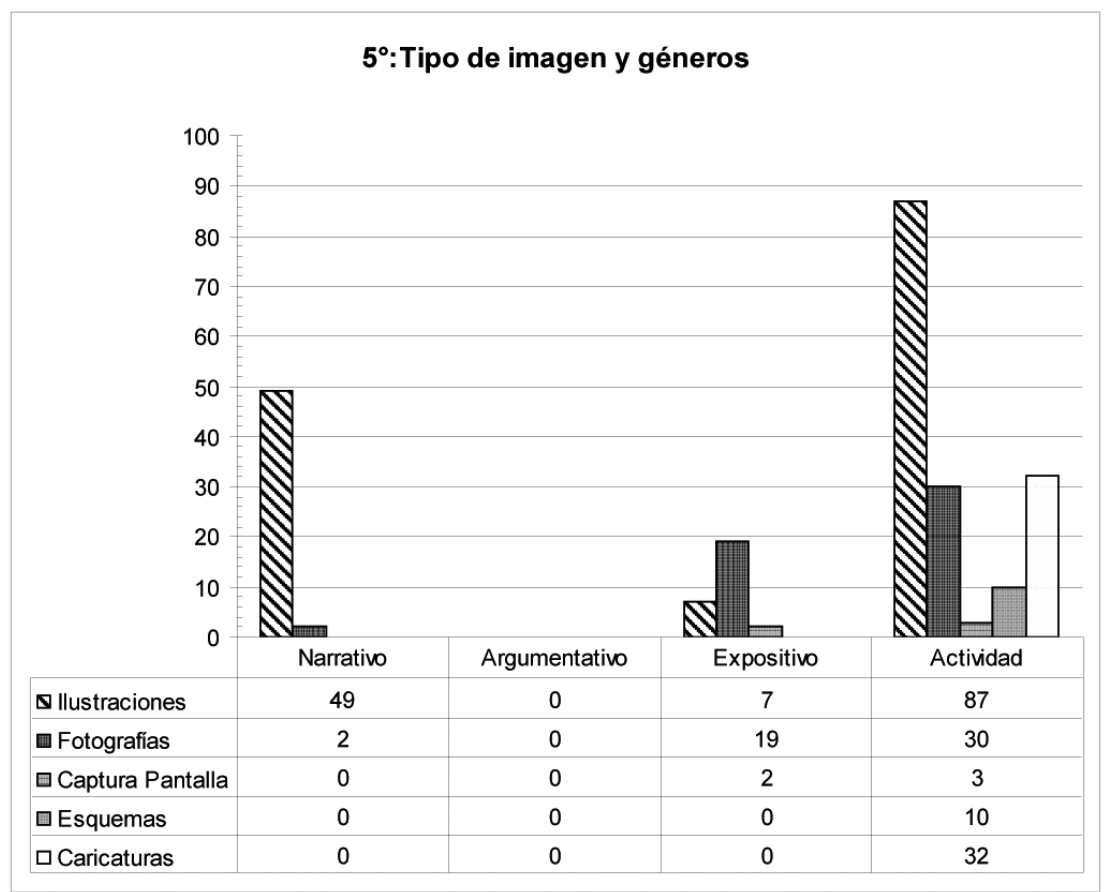

Gráficos 2: Tipos de imágenes y Géneros en $6^{\circ}$ básico

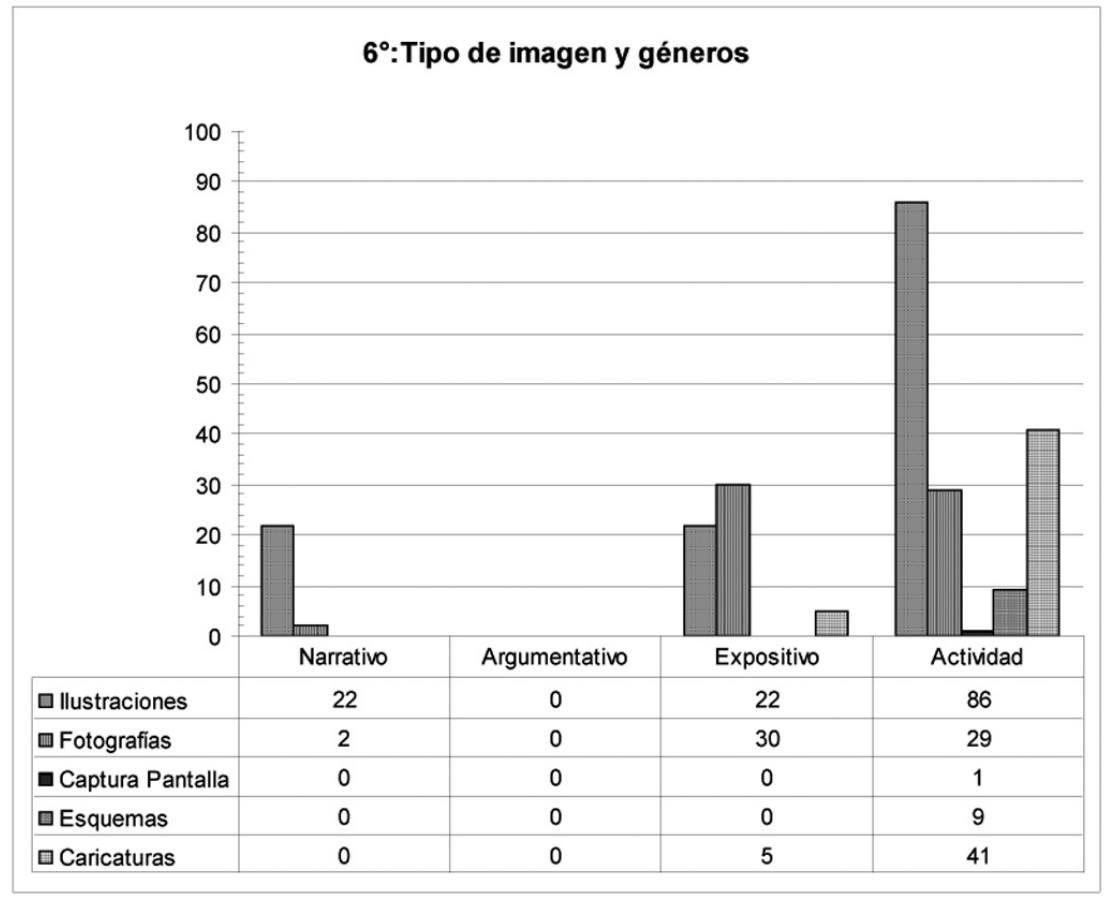


Como se aprecia en los gráficos 1 y 2 . La mayor cantidad de imágenes están relacionadas con el género actividad tanto en $5^{\circ}$ como en $6^{\circ}$ básico. No debe extrañar que la congregación de los distintos tipos de imágenes se presente frente a este género, dado que este es el más recurrente en los textos de estudio y es el que da la estructuración y forma a este macro-género. En otros términos, las actividades son los ejes articuladores del texto escolar puesto que son las instancias en las que los estudiantes interactúan con estos materiales didácticos en distintos niveles: uno instruccional, en el que se reciben las indicaciones de los que se debe hacer; uno de adquisición de contenidos conceptuales (en el que los estudiantes aprenden ciertos contenidos propios de la disciplina) y, por último, uno de ejercitación de las habilidades que subyacen a los $\mathrm{OF}$ y $\mathrm{CMO}$, en el que los alumnos ponen en práctica distintas competencias que les permiten comprender y producir textos orales y escritos. Una apreciación respecto de esta reflexión, es que los tres niveles del género actividad están intrínsicamente en este y pueden darse de manera independiente de las imágenes que los acompañan, en este sentido, no tendría mucha relevancia si hay una fotografía o una ilustración, puesto que no debiese interesar si el lenguaje icónico es más o menos cercano a la realidad. Ahora bien, desde una perspectiva multimodal, las imágenes construyen una realidad casi de la misma manera que el lenguaje verbal, por lo tanto, no tiene el mismo sentido motivar a la lectura con un esquema que con una fotografía, puesto que el primero sirve para potenciar un método de estudio, mientras que la segunda puede ayudar a delimitar el modelo de situación que los lectores elaboran al momento de comprender.

En lo que respecta a la argumentación, no se presentan imágenes asociadas a este género discursivo. Se hipotetiza que esto se debe a dos razones fundamentalmente. Primero, este género no requiere de la explicación ni complementación mediante la utilización de imágenes, y la segunda, se debe a que en los Objetivos Fundamentales propuestos por el Mineduc para estos niveles de enseñanza, la argumentación no es un tópico que se aborde de manera explícita.

Explicando los otros géneros, los datos muestran que las fotografías son las imágenes que más se asocian al género expositivo. En los textos escolares de los dos cursos analizados la cantidad de imágenes es de 30 para $6^{\circ}$ básico y 19 para $5^{\circ}$ básico. Si se piensa en las características de la exposición: claridad y objetividad; la fotografía (al ser una representación de la realidad empírica) es el tipo de imagen que mejor asume la forma de representar el mundo de manera objetiva y clara. Por último, 
Análisis descriptivo de Textos Escolares de Lenguaje y Comunicación / Felipe Pereira

Henríquez y Guillermo González

el género narrativo tiene asociada una gran cantidad de imágenes que preferentemente son ilustraciones. Tal como se mencionó antes, la descripción conceptual señala que estas son tipos de imágenes en la que prima el trazo manual, es decir, son representaciones de la realidad, pero esencialmente dibujadas. Su conexión con lo narrativo, especialmente en $5^{\circ}$ básico, puede deberse a que este género se concentra en textos tales como las fábulas, los cuentos y las leyendas, por lo tanto, el lenguaje visual que representa al escrito debe "dibujarse" debido a que no puede ser extraído de la realidad.

\subsection{Funciones de las imágenes}

Un último punto de esta presentación de resultados, está asociado a las funciones de las imágenes en los textos escolares. En los gráficos 3 y 4 , se presenta la distribución de estas en todo el texto escolar, independientemente del tipo de estas.

Gráfico 3: Funciones de las imágenes en $5^{\circ}$ básico

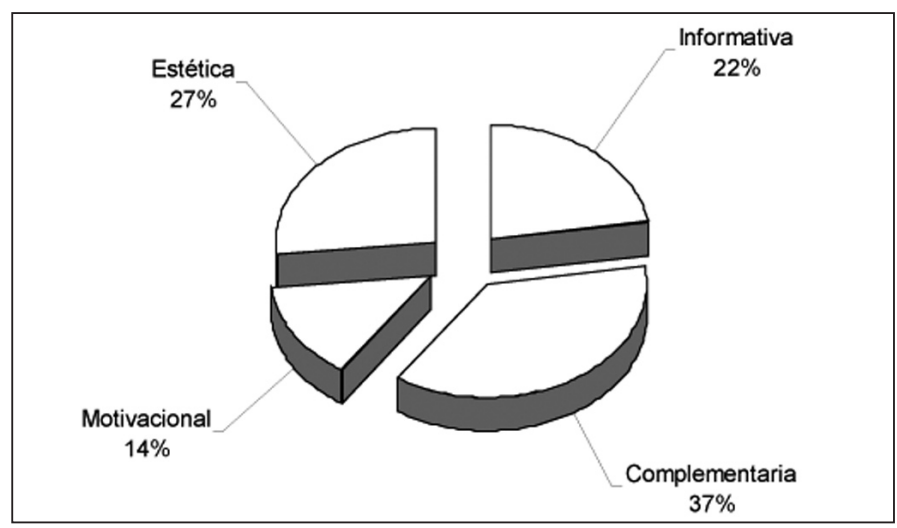

Gráfico 4: Funciones de las imágenes en $6^{\circ}$ básico
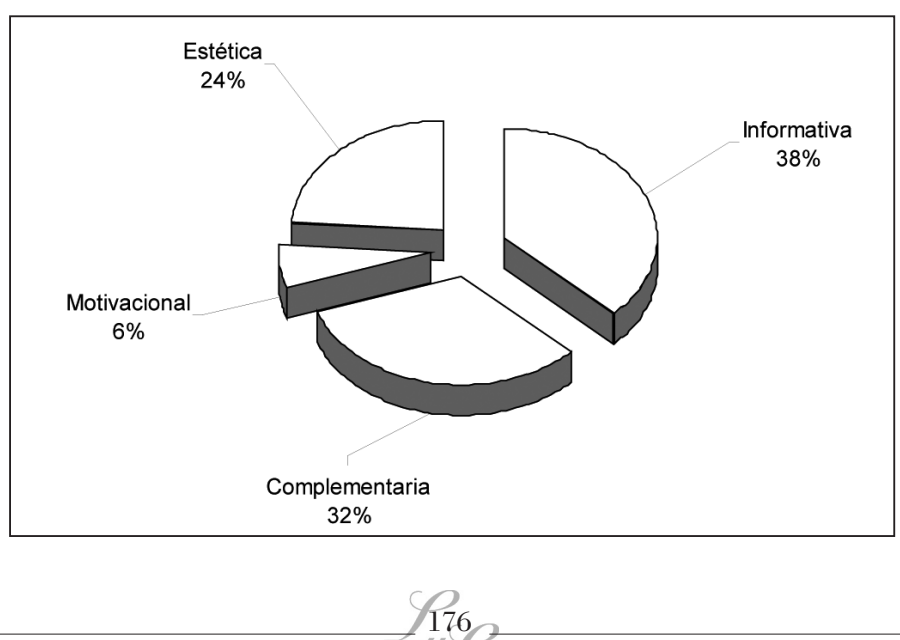
De acuerdo a estos gráficos, la función complementaria es la que se da mayoritariamente en el texto de $5^{\circ}$ básico, mientras que la función informativa es la que más se presenta en $6^{\circ}$. Cada una de estas funciones alcanza un $37 \%$ y un $38 \%$, respectivamente. Las diferencias entre ambos cursos se deben a que el texto de $6^{\circ}$ básico contiene una mayor cantidad de imágenes que agregan información anexa al texto verbal, mientras que en quinto, estas entregan casi la misma información que los textos verbales escritos.

En las Tablas 3 y 4, mostradas a continuación, se especifican tanto en términos numéricos como de porcentajes, cuáles son las funciones más específicas que los distintos tipos de imágenes cumplen en relación con los textos verbales escritos.

\begin{tabular}{|l|c|c|c|c|c|c|c|c|c|c|}
\hline $5^{\circ}$ Básico & \multicolumn{2}{|c|}{ Ilustraciones } & \multicolumn{2}{|c|}{ Fotografías } & \multicolumn{2}{c|}{ Captura Pantalla } & \multicolumn{2}{|c|}{ Esquemas } & \multicolumn{2}{c|}{ Caricaturas } \\
\hline FUNCIONES & $\mathrm{N}^{\circ}$ & $\%$ & $\mathrm{~N}^{\circ}$ & $\%$ & $\mathrm{~N}^{\circ}$ & $\%$ & $\mathrm{~N}^{\circ}$ & $\%$ & $\mathrm{~N}^{\circ}$ & $\%$ \\
\hline Informativa & 14 & $9,8 \%$ & 9 & $17,6 \%$ & 3 & $60 \%$ & 2 & $20 \%$ & 26 & $81,3 \%$ \\
\hline Complementaria & 51 & $35,7 \%$ & 26 & $51,0 \%$ & 2 & $40 \%$ & 5 & $50 \%$ & 5 & $15,6 \%$ \\
\hline Motivacional & 19 & $13,3 \%$ & 12 & $23,5 \%$ & 0 & $* * *$ & 3 & $30 \%$ & 0 & $* * *$ \\
\hline Estética & 59 & $41,3 \%$ & 4 & $7,8 \%$ & 0 & $* * *$ & 0 & $* * *$ & 1 & $3,1 \%$ \\
\hline & 143 & $100 \%$ & 51 & $100 \%$ & 5 & $100 \%$ & 10 & $100 \%$ & 32 & $100 \%$ \\
\hline
\end{tabular}

\begin{tabular}{|l|c|c|c|c|c|c|c|c|c|c|c|}
\hline $6^{\circ}$ Básico & Ilustraciones & \multicolumn{2}{|l|}{ Fotografías } & Captura Pantalla & \multicolumn{2}{|c|}{ Esquemas } & \multicolumn{2}{c|}{ Caricaturas } \\
\hline FUNCIONES & $\mathrm{N}^{\circ}$ & $\%$ & $\mathrm{~N}^{\circ}$ & $\%$ & $\mathrm{~N}^{\circ}$ & $\%$ & $\mathrm{~N}^{\circ}$ & $\%$ & $\mathrm{~N}^{\circ}$ & $\%$ \\
\hline Informativa & 24 & $18,5 \%$ & 23 & $37,7 \%$ & 1 & $100 \%$ & 6 & $66,7 \%$ & 38 & $82,6 \%$ \\
\hline Complementaria & 49 & $37,7 \%$ & 21 & $34,4 \%$ & 0 & $* * *$ & 3 & $33,3 \%$ & 7 & $15,2 \%$ \\
\hline Motivacional & 12 & $9,2 \%$ & 3 & $4,9 \%$ & 0 & $* * *$ & 0 & $* * *$ & 1 & $2,2 \%$ \\
\hline Estética & 45 & $34,6 \%$ & 14 & $23,0 \%$ & 0 & $* * *$ & 0 & $* * * *$ & 0 & $* * *$ \\
\hline & 130 & $100 \%$ & 61 & $100 \%$ & 1 & $100 \%$ & 9 & $100 \%$ & 46 & $100 \%$ \\
\hline
\end{tabular}

La descripción más pormenorizada de las funciones y los tipos de imágenes, permite apreciar que en $5^{\circ}$ básico el 41,3\% de las ilustraciones tienen una función estética; el 35,7 una función complementaria; el 13,3 una función motivacional y solo el 9,8\% una función informativa. En $6^{\circ}$ básico, se produce un fenómeno similar debido a que el 34,6\% tiene una función estética y el 37,7\% complementaria. Siendo la función motivacional la más baja en este curso y en relación a este tipo de imágenes. A partir de estos resultados, se puede mencionar que en ambos cursos, las ilustraciones están dispuestas como adornos que permiten embellecer el texto más que como elementos que añaden información adicional o complementaria a los textos verbales escritos.

Las fotografías por su parte desempeñan una función complementaria mayoritariamente y luego motivacional en $5^{\circ}$ básico, alcanzando valores 
Análisis descriptivo de Textos Escolares de Lenguaje y Comunicación / Felipe Pereira

Henríquez y Guillermo González

de $51 \%$ y $23,5 \%$, respectivamente. En $6^{\circ}$ básico en cambio, la principal función de este tipo de imágenes es informativa (37,7\%) y luego complementaria $(34,4 \%)$. Solo 3 fotografías tienen una función motivacional en este curso. Las caricaturas, en ambos cursos, tienen una función predominantemente informativa. Mientras que los esquemas, se presentan en una función informativa en $6^{\circ}$ y complementaria en $5^{\circ}$ básico.

Los datos presentados permiten apreciar que los distintos tipos de imágenes cumplen diferentes funciones al presentarse junto al texto verbal escrito. Estas funciones van desde el plano de la informatividad (cuando se agrega más información a la expresada verbalmente), hasta una función estética, en la cual las imágenes, independiente de su tipo, están dispuestas a lo largo del texto escolar como elementos que adornan y no aportan ninguna información a lo que se lee.

\section{Conclusiones}

En el presente artículo se ha presentado un Modelo Multimodal de Análisis Descriptivo de Textos escolares (MADETEC), el que ha sido diseñado para describir los textos de estudio entregados por el Ministerio de Educación de Chile a los diferentes establecimientos educacionales de carácter municipal. Este modelo, sin embargo, no solo se constituye como un instrumento descriptivo sino como una guía para análisis de textos multimodales. De esta manera, se busca posibilitar una mejor comprensión de los diferentes modos de representación que constituyen a los libros de texto, sean estos imágenes o textos verbales escritos. Asimismo, se pretende determinar y esclarecer las distintas relaciones subyacentes que existen entre el material visual y el material verbal escrito con la finalidad de describir tanto cuantitativa como cualitativamente los textos multimodales que se utilizan, por una parte, en el contexto educativo, mientras que por otra, en el contexto cotidiano.

En la misma línea de lo planteado antes, uno de los hallazgos de esta investigación es que se ha podido describir empíricamente textos escolares utilizados en contextos reales de enseñanza-aprendizaje, lo que permite tener una perspectiva respecto de cómo están configurados los textos de estudio que utilizan nuestros estudiantes. Indudablemente, esta perspectiva puede ser enriquecida al analizar textos de distintas disciplinas, niveles e incluso editoriales.

Uno de los puntos de partida de MADETEC, es que se considera que las imágenes no deben ser relegadas a un plano secundario sino que 
deben considerarse como modos portadores de significados que pueden ser analizados e interpretados de manera similar a como se comprenden los textos verbales escritos. Estos modos icónicos aportan información que no está descrita verbalmente, por lo tanto, se transforman en modos portadores de información que resultan relevantes en el proceso de enseñanza-aprendizaje. Una de las problemáticas que la literatura especializada ha abordado con respecto a las imágenes, es que estas se utilizan en una función ornamental y estética principalmente, razón por la cual, ni los docentes ni los estudiantes las consideran como modos que transmiten significados y que permiten comprender, recordar y aclarar ciertos conceptos que se presentan desde el modo verbal escrito (Pereira 2007, 2008).

En estrecha relación con lo planteado en el párrafo anterior, la aplicación de MADETEC en los textos de $5^{\circ}$ y $6^{\circ}$ Básico de Lenguaje y Comunicación de la editorial Cal y Canto, permite apreciar que estos materiales didácticos contienen en su diseño una amplia gama de tipos de imágenes que a su vez cumplen distintas funciones que van desde la complementaria a la estética. Llama la atención, de todas formas, que las editoriales y los equipos que diseñan los textos escolares dispongan en gran medida de imágenes que se limitan a cumplir un función estética o motivacional, más que una función de complementación o informativa. De acuerdo a las definiciones conceptuales de estas, ambos tipos de funciones establecen una relación con el lenguaje verbal escrito, complementándolo e incluso dando más información de la que está expresada verbalmente, sin embargo, los datos presentados permiten plantear que resulta más relevante adornar un texto escolar con imágenes (como en el caso de $5^{\circ}$ básico), más que intencionar una comprensión y una reflexión de ambos modos.

A partir de estas reflexiones, sustentadas en la alta aparición de imágenes con diversas funciones en los textos escolares, es indudable que los textos multimodales impresos son actualmente materiales de amplia difusión entre los estudiantes de los distintos niveles y en los distintos subsectores. Aunque es importante mencionar que no solo están los textos de estudio entregados por agentes externos a los establecimientos sino que también las guías didácticas, las pruebas y los materiales de lectura diseñados por cada uno de los docentes en su práctica cotidiana. Un problema que emerge en estos materiales didácticos es que tienden a reproducir los modelos dados por los textos escolares. Esto lleva a los docentes a poner las imágenes en funciones estéticas o motivacionales, pero no en otras funciones que permitan sacar el real provecho a las 
Análisis descriptivo de Textos Escolares de Lenguaje y Comunicación / Felipe Pereira

Henríquez y Guillermo González

imágenes como modos de transmisión de significados. En este sentido, uno de los hallazgos importantes de esta investigación es que existen distintas funciones asociadas a distintos tipos de imágenes en los textos que se utilizan en el ámbito educativo. Obviamente, para ser capaces de utilizarlas se requiere cimentar los principios de una alfabetización visual que permita a los docentes leer, analizar y reflexionar sobre el lenguaje icónico y de esta forma mejorar los procesos de enseñanza-aprendizaje.

\section{Referencias bibliográficas}

Ajagan, L. (2007). Evaluando las evaluaciones. En Primer Seminario de textos escolares, realizado por el Componente de textos escolares de la Unidad de Currículo y gestión del MINEDUC (pp. 326-331). Santiago: LOM.

Alzate, M. (2000). ¿Cómo leer un texto escolar?: Texto, paratexto e imágenes. Revista de ciencias humanas. 20.

Bajtin, M. (2005). Estética de la creación verbal. Buenos Aires: Siglo XXI.

Calsamiglia, H. \& Tusón, A. (1999). Las cosas del decir. Manual de análisis del discurso. Barcelona: Ariel.

Ciapuscio, G. E. (1994). Tipos Textuales. Buenos Aires: Universidad de Buenos Aires.

Colás Bravo, M. (1989). El libro de texto y las ilustraciones: enfoques y perspectivas en la investigación educativa. Enseñanza, 7, 41-50.

Colle, R. (1993). Iniciación al lenguaje de la imagen. Santiago: Ediciones Universidad Católica de Chile.

Eubanks, P. (1999). Learning to be a connoisseur of books: Understanding picture books as an art medium. Art education, 52(6), $38-44$.

Eyzaguirre, B. \& Fontaine, L. (1997). El futuro en riesgo: nuestros textos escolares. Estudios Públicos, 68, 339-354.

Fontaine, L. \& Eyzaguirre, B. (1997). Por qué es importante el texto escolar. Estudios Públicos, 68, 355-369.

Haensch, G. (1982). La lexicografía: De la lingüística teórica a la lexicografía práctica. Madrid: Gredos.

(1997). Los diccionarios del español en el umbral del siglo XX. Salamanca. España: Universidad de Salamanca. 
Hymes, D. (1972). Models of the interaction of language and social life. En J. Gumperz \& D. Hymes (eds). Directions in sociolinguistics. The ethnography of communication. Nueva York.

Jewitt, C. (2003). Computer-mediated learning: The multimodal construction of mathematical entities on screen. En C. Jewitt \& G. Kress (Eds.), Multimodal literacy (pp. 34-55). New York: Peter Lang.

$\&$ Kress, G. (2003). Introduction. En C. Jewitt \& G. Kress (Eds.), Multimodal literacy (pp. 1-18). New York: Peter Lang.

Kress, G. (2003). Literacy in the new media age. London: Routledge.

(2004). Reading images: Multimodality, representation and new media. Information Design Journal + Document design, 12(2), 110-119.

(2005). El alfabetismo en la era de los nuevos medios de comunicación. Málaga: Ediciones Aljibe.

\& Van Leeuwen, T. (1996). Reading images, the grammar of visual design. London: Routledge.

$\&$ _ (2001). Multimodal discourse: The modes and media of contemporary communication. London: Arnold.

Mineduc (2008). Politica de Textos Escolares. Gobierno de Chile: Santiago.

Maverns, D. (2003). Communicating meanings through image composition, spatial arrangement and links in primary school students mind maps. En C. Jewitt \& G. Kress (Eds.), Multimodal literacy (pp. 19-33). New York: Peter Lang.

Otero, M. \& Greca, I (2004). Las imágenes en los textos de física. Cad. Brás. Ens. Fís., v. 21, 1, 35-64.

Parodi, G. (2008). Géneros del discurso escrito: Hacia una concepción integral desde una perspectiva sociocognitiva. En G. Parodi (Ed.), Géneros académicos y géneros profesionales: Accesos discursivos para saber y hacer (pp. 17-37). Valparaíso: Ediciones Universitarias de Valparaíso.

, Venegas, R., Ibáñez, R. \& Gutiérrez, R. (2008). Géneros del discurso en el corpus PUCV-2006: Criterios, definiciones y ejemplos. En G. Parodi (Ed.), Géneros académicos y 
Análisis descriptivo de Textos Escolares de Lenguaje y Comunicación / Felipe Pereira

Henríquez y Guillermo González

géneros profesionales: Accesos discursivos para saber y hacer (pp. 39-73). Valparaíso: Ediciones Universitarias de Valparaíso.

Perales, J. \& Romero, J. (2005). Procesamiento conjunto de lenguaje e imágenes en contextos didácticos: una aproximación cognitiva. Anales de Psicología, 21, 1, 129-146.

Pereira, F. (2007). La comprensión de textos narrativos mono y multimodales leidos en pantalla de computador y papel. Tesis Doctoral, Pontificia Universidad Católica de Valparaíso, Valparaíso, Chile.

(2008). Hacia la comprensión del texto narrativo multimodal digital. En M. Farías \& K. Oblinovic (Comp.), Aprendizaje Multimodal -Multimodal learning-(pp. 119-135). Publifahu: Santiago de Chile.

Prendes, M. (1996). Análisis de imágenes en textos escolares: descripción y evaluación. Revista Píxel-Bit. Revista de Medios y Educación. 6.

(2001). Evaluación de manuales escolares. Revista Píxel-Bit. Revista de Medios y Educación. 16.

\& Solano, I. (2009). Herramienta de Evaluación de Material Didáctico Impreso. Revisado en enero de 2009 [en línea]. Disponible en: http://tecnologiaedu.us.es/nweb/htm/ pdf/paz7.pdf

Pró, M. (2003). Aprender con imágenes: incidencia y uso de la imagen en las estrategias de aprendizaje: Barcelona: Paidós.

Scolari, C. \& March, J. (2004), Hacia una taxonomía de la info-visualización. Revisado en enero de 2009 [en línea]. Disponible en: ttp://www.modernclicks.net/pdf/scolari-march.pdf

Vilches, L. (1995). La lectura de la imagen. Prensa, cine, televisión. Barcelona: Paidós. 